\title{
Caltha palustris L. Bitkisinin Çiçek ve Yaprak Kısmının Uçucu Yağlarının Kimyasal Bileşimi ve Antimikrobiyal Aktiviteleri
}

\author{
Chemical Composition and Antimicrobial Activity of Essential Oil From the Flower and \\ Leaf of Caltha palustris L.
}

\author{
Tayyibe Beyza YÜCEL ${ }^{* 1, a}$, Seda FANDAKLI ${ }^{2, b}$, Salih TERZIOĞLU ${ }^{3, c}$, Nurettin YAYLI ${ }^{4, d}$ \\ ${ }^{I}$ Giresun Üniversitesi, Espiye Meslek Yüksekokulu, 28600, Giresun \\ ${ }^{2}$ Avrasya Üniversitesi, Sağllk Hizmetleri Meslek Yüksekokulu, 61000, Trabzon \\ ${ }^{3}$ Karadeniz Teknik Üniversitesi, Orman Mühendisliği, 61080, Trabzon \\ ${ }^{4}$ Karadeniz Teknik Üniversitesi, Eczacllk Fakültesi, 61080, Trabzon
}

• Geliş tarihi / Received: 28.02.2018 • • Düzeltilerek geliş tarihi / Received in revised form: 22.06.2018 • Kabul tarihi / Accepted: 25.07 .2018

\begin{abstract}
$\ddot{O} z$
Caltha palustris L. (Ranunculaceae) bitkisinin çiçek ve yaprak kısımlarının uçucu yağları Clevenger aparatlı subuharı destilasyonu yöntemiyle elde edilmiştir. Elde edilen uçucu yağların kimyasal bileşenleri, GC-FID ve GC-MS teknikleriyle aydınlatılmıştır. C. palustris bitkisinin çiçek ve yaprak kısımlarının uçucu yağlarında sırasıyla; toplam 52 ve 36 bileşik bulunmuş olup; sırasıyla \%95.34 ve \%82.4'lük kısımları aydınlatılmıștır. Çiçek kısmının uçucu yağının başlıca bileşenleri; oktadekanol (\%25.40), fitol (\%18.56), octanol (\%9.01), neofitadien (\%3.65), alkol (\%36.30) ve terpenoit (\%22.62) bileşiklerden oluştuğu; yaprak kısmının uçucu yağ analizinde ise ise heptadekan (\%10.05), fitol (\%8.94), oktadekanol (\%6.3), heneikosan (\%3.03), (E)- $\beta$-farnesan (\%1.34) gibi ağırlıklı olarak hidrokarbon (\%30.89) ve terpenoit (\%14.59) bileşiklerden oluştuğu tespit edilmiştir $C$. palustris bitkisinin çiçek ve yaprak kısımlarından elde edilen uçucu yağların antimikrobiyal aktiviteleri, 8 adet Gram pozitif ve Gram negatif bakteri ve mantarlara karşı araştırılmıştır. Uçucu yağların, Candida albicans ve Saccharomyces cerevisiae'ya $(8-14 \mathrm{~mm})$ karşı antimikotik aktivite gösterdiği tespit edilmiştir.
\end{abstract}

Anahtar kelimeler: Antimikrobiyal aktivite, Caltha palustris, GC-FID/MS, Uçucu yağ

\begin{abstract}
The essential oils from flower and leaf of Caltha palustris L. were obtained by hydrodistillation with Clevenger-type apparatus and analyzed by GC-FID and GC-MS. Fifty-two compounds in the oil resulted from flower of C. palustris, representing $95.34 \%$ and thirty-six compounds in the oil obtained from leaf of C. palustris, representing $82.4 \%$, were identified. The main components of the volatile oil of the flower part are octadecanol (25.40\%), phytol (18.56\%), octanol (9.01\%) and neophytadien (3.65\%) which are alcohols (36.30\%) and terpenoids (22.62\%) type compounds. It was found that the volatile oil of the leaf part consisted predominantly of hydrocarbons (30.89\%) and terpenoid (14.59\%) compounds such as heptadecane (10.05\%), phytol (8.94\%), octadecanol (6.3\%), heneicosane (3.03\%) and (E)- $\beta$-farnesane (1.34\%) were major constituents. The antimicrobial activities of the essential oils obtained from flower and leaf parts of C. palustris plant were investigated against 8 Gram positive and Gram-negative bacteria and fungi. It has been determined that essential oils have antimycotic activity against Candida albicans and Saccharomyces cerevisiae (8-14 mm), respectively.
\end{abstract}

Keywords: Antimicrobial activity, Caltha palustris, GC-FID/MS,Essential oil

\footnotetext{
*a Tayyibe Beyza YÜCEL; beyza.yucel@giresun.edu.tr; Tel: (0454) 31014 30-6410; orcid.org/0000-0002-2632-8325

${ }^{b}$ orcid.org/0000-0002-8199-3336 $\quad$ orcid.org/0000-0003-4146-3514 $\quad$ orcid.org/0000-0003-4174-3014
} 


\section{Giriş}

Ülkemizde otsu ve tırmanıcı odunsu taksonlara sahip olan Ranunculaceae familyası 20 cinse ait toplam 204 türle (Davis, 1965; Güner vd., 2012) Türkiye florasının en geniş familyalarından biridir. Caltha L. (Lilpar) cinsi dünyada 6 türe sahiptir (URL-1). Cins, ülkemizde sadece Caltha palustris L. Türü ile temsil edilmekte; Batı, Doğu Karadeniz Bölümleri, Orta Kızılırmak Bölümü ve Doğu Anadolu Bölgemizde, sslak çayırlar ve akarsu kenarlarında, 1700-3600 m yükseltilerde yayılış göstermektedir (Güner vd., 2012). C C. palustris dünyada ise Bulgaristan, Kafkaslar ile Kuzey ve Kuzeybatı İran'da doğal olarak yayılmaktadır (Davis, 1965).

C. palustris fenolik, alkaloid ve siyanogenik bileşikler bakımından zengin olup antispazmodik ve sakinleştirici olarak kullanılmaktadır (Figurkin vd., 1978; Resursy, 1980; Dickmann vd., 1982; Baytop, 1984; Ellnain-Wojtaszek vd., 1991; Ali vd., 2011). Bileşiminde protoanemanin, glavonoids, tanen, saponin içermekte olup protoanemaninden kaynaklı kuvvetli zehir etkisi göstermesinden dolayı dahilen kullanılması sakıncalıdır (Birinci, 2008; Wink, 2009). Ayrıca 6 farklı viral hastalı tedavisinde kullanılan antioksidan aktiviteye sahip triterpen saponinler; C. palustris bitkisinde bulunmaktadır (Smith Jr., 1968; Vugalter vd., 1988; Roner vd., 2007; Küçükkurt ve Fidan, 2008).

Yapılan literatür araştırmasında Caltha palustrisin kök korteksi gelişimi ve yapısı, stres altındaki marş-marigold'da (C. palustris) protoanemonin birikimin HPLC ile tayini, C. palustris L.'nin Ramet dağılımı, yaprak morfometrisi ve elementel bileşimi çalışmaları, çevresel kirlilik göstergelerine ait çalışmalar ve Türkiye'de bulunan faydalı bitkiler ve içeriklerinin tayinine ait çalışmalar ve bitki içeriğindeki glikozidlerin ve triterpen saponin tayinlerine dair çalışmalara rastlanmıştır (Bhandari vd., 1984; Bonora vd., 1987a,b; Toth vd.,1999; Baykal vd., 1999; Seago Jr vd., 2000; Ekmekçigil, 2006; Van der Welle vd., 2007; Birinci, 2008; Suszko and ObminskaMrukowiez., 2013).

C. palustris bitkisinin çiçekteki erkek organ (anter) kısmının uçucu bileşenleri termal desepsiyon GC-MS yöntemine göre yapılmıştır (Jürgens ve Dötterl, 2004). Bunun yanında $C$. palustris var. alba bitkisinin çözücü ekstrelerinin biyolojik aktivite tayin çalışmasının yapıldığ görülmüştür (Mubashir vd., 2014). Fakat Türkiye'de yetişen $C$. palustris bitkisinin çiçek ve yaprak kısımlarının uçucu yağ analizi ve antimikrobiyal aktivite tayinine ait, literatürde herhangi çalışmaya rastlanmamıştır.

\section{Materyal ve Yöntem}

\subsection{Bitki Numunesi}

Çalışma materyali olan ve $C$. palustris $\mathrm{L}$. türüne ait örnekler Gümüşhane ili, Zigana yöresi, Limni Gölü üstleri, 2042 m, UTM 50 DATUM (0535364, 4496258), nemli çayırlar-akarsu kenarlarından 2015 yılı Mayıs ayında toplanmıştır ve toplanan örneklere ait herbaryum materyali Karadeniz Teknik Üniversitesi Orman Fakültesi Herbaryumu (KATO 16796)'na konmuştur.

\subsubsection{Uçucu Yă̆ Ekstraksiyon İşlemi}

Toplanan C. palustris bitkisi taze iken çiçek, yaprak kısımları ayrıldı. Toplanan bitkinin çiçek (110 g) ve yaprak (100 g) kısmı alınarak, 1L'lik destilasyon balonuna konuldu ve üzerine $500 \mathrm{~mL}$ saf su ilave edildi. Clevenger tip geri soğutucu aparatına bağlı su buharı destilasyonu sistemine bağl1 soğutma banyosu ile $-15{ }^{\circ} C^{\prime}$ ye soğutulan sistemle, bitkinin çiçek ve yaprak kısımları 4 saat ssitılarak uçucu bileşenler destilasyon ile ayrıldı ve uçucu yağlar; HPLC saflıktaki $1 \mathrm{~mL} n$-hekzan çözücüsüyle beraber alınarak kahverengi viallere konuldu. Susuz $\mathrm{Na}_{2} \mathrm{SO}_{4}$ ile suyu uzaklaştırılan uçucu yağlar, kalitatif ve kantitatif analiz için GC/MS- GC/FID ve biyolojik aktivite tayini için 4-6 ${ }^{\circ} \mathrm{C}$ 'de saklandı (Yaylı vd., 2010; Fancelloa vd., 2017).

\subsubsection{Uçucu Yağ Ekstraksiyon İşlemi}

C. palustris bitkisi çiçek ve yaprak kısımlarından elde edilen uçucu yağ ekstrelerinin GC/FID ve GC/MS analizleri, Agilent-5973 Network Sistem marka cihaz ile literatürde gösterildiği gibi yapılmıştır (Üçüncü vd., 2016; Yücel vd., 2017).

\subsubsection{Bileşenlerin Tanımlanmast}

GC/FID ve GC/MS cihazında tayin edilen bileşenlerin tutunma indeksleri Kovats yöntemi belirlenmiş olup standartlar bileşikler olarak $n$ alkanlar $\left(\mathrm{C}_{6}-\mathrm{C}_{32}\right)$ kullanılmıştır. Uçucu yağların kimyasal bileşenleri, bileşenlerin kütle spektrumları ile kütle spektrumu kütüphaneleri olan NIST, Wiley [NIST Chemistry Webbook] ve standart bileşikler (limonen, linalool, $\alpha$-terpineol, geraniol, tridekan, tetradekan, pentadekan, nonadekan, eikosan, heneikosan) kullanarak ve literatürdeki kütle spektrumları ile karşılaştırılarak 
belirlenmiş̧ir (Adams 2004; Radulovi'c vd., 2008, Tyagi vd., 2017; Fancello vd.,2017).

\subsubsection{Antimikrobiyal Aktivite Belirlenmesi}

Elde edilen uçucu yağların antimikrobiyal aktivite testleri için kullanılan test mikroorganizmalar Escherichia coli ATCC35218, Yersinia pseudotuberculosis ATCC911, Pseudomonas aeruginosa ATCC43288, Enterococcus faecalis ATCC29212, Staphylococcus aureus ATCC25923, Bacillus cereus 709 Roma, Candida albicans ATCC60193 ve Saccharomyces cerevisiae) RSKK 251 olup Refik Saydam Hıfzisıhha Enstitüsünden temin edilmiştir. Antimikrobiyal aktivite testleri çift mikrodilüsyon metodu kullanılmış ve inhibisyon zon çapları (mm) belirlenmiştir. Uçucu yağ ekstraktları tartılarak hekzan ile çözülmüş ve 27.000-65.000 $\mu \mathrm{g} / \mathrm{mL}$ özüt stok solüsyonu hazırlanmıştır. Antibakteriyel ve antifungal testler sirasiyla $\mathrm{pH}$ 7.0'de Mueller-Hinton (MH) (Difco, Detroit, MI) ve $\mathrm{pH}$ 7.0'de tamponlanmıș Maya Azot Bazında (Difco, Detroit, MI) yürütülmüştür. Mikro seyreltme test plakaları 18-24 saat boyunca 35 ${ }^{\circ} \mathrm{C}$ 'de inkübe edilmiştir. Standart antibakteriyel ve antifungal ilaç olarak ampisilin $(10 \mu \mathrm{g})$ ve flukonazol (5 $\mu \mathrm{g})$ kullanılmıştır (Cansu vd., 2011).
Kontrol çözücüsü olarak 1:10 oranında seyreltilmiş Dimetilsülfoksid kullanılmıştır.

\section{Bulgu, Sonuç ve Tartışma}

Taze halde çalışılan $C$. palustris bitkisinin çiçek ve yaprak kısımlarınının subuharı destilasyonu yöntemi ile ekstraksiyon işlemi sonucunda sirasiyla; $\% 0.017$ ve $\% 0.015$ verimle $18.7 \mathrm{mg}$ ve $14.9 \mathrm{mg}$ uçucu yağ elde edildi. C. palustris bitkisinin çiçek ve yaprak kısmının uçucu yağlarının GC/MS analiz sonuçları Tablo 1'de verilmekte olup sırasıyla; 52 ve 34 uçucu organik bileşik \%95.34 ve \%82.4 oranında aydınlatılmıştır.

Uçucu yă̆ içeriğindeki aydınlatılan bileşikler terpenler, terpenoidler, terpenoid benzeri bileşikler, hidrokarbonlar, alkoller ve diğer bileşikler olmak üzere 6 sınıfta gruplandırılmıştır (Tablo 2). Çiçek kısmında ana bileşen sınıfı $\% 36.30$ oranıyla alkoller, yaprak kısmında ise $\% 30.89$ oranında hidrokarbonlar olarak bulunmuştur. Çiçek kısmının uçucu yağının ana bileşenleri oktadekanol (\%25.40), fitol (\%18.56) ve oktanol (\%9.01), yaprak kisminda ana bileşenleri ise heptadekan (\%10.05), fitol (\%8.94) ve oktadekanol (\%6.3) olarak bulunmuştur.

Tablo 1. C. palustris Bitkisinin Çiçek ve Yaprak Kısmının Uçucu Yağ Bileşenleri

\begin{tabular}{|c|l|l|c|c|c|c|}
\hline No & Alık. Zam. & Bileşiğin Ad1 & $\begin{array}{c}\text { Çiçek } \\
\% \text { Alan }\end{array}$ & $\begin{array}{c}\text { Yaprak } \\
\% \text { Alan }\end{array}$ & $\begin{array}{c}\text { Literatür } \\
\text { RI }\end{array}$ & $\begin{array}{c}\text { Deneysel } \\
\text { RI }\end{array}$ \\
\hline \multicolumn{7}{|c|}{ Terpenler } \\
\hline 1 & 7.146 & $\alpha$-Terpinen & 0.74 & - & 1017 & 1020 \\
\hline 2 & 7.377 & o-Simen & 0.66 & - & 1026 & 1030 \\
\hline 3 & 7.548 & Limonen & 0.59 & - & 1029 & 1033 \\
\hline 4 & 8.285 & $(E)$ - $\beta$-Osimen & 0.17 & - & 1050 & 1054 \\
\hline 5 & 8.628 & $\gamma$-Terpinen & 0.57 & - & 1060 & 1064 \\
\hline 6 & 9.864 & $\alpha$-Terpinolen & 1.18 & & 1089 & 1093 \\
\hline 7 & 22.214 & Farnesan & - & 0.76 & 1378 & 1381 \\
\hline 8 & 25.895 & $(E)$ - $\beta$-Farnesen & - & 1.34 & 1457 & 1460 \\
\hline 9 & 24.037 & $\alpha$-Santalen & 0.21 & - & 1418 & 1422 \\
\hline 10 & 24.766 & $\alpha$-Cis-Bergamoten & 0.36 & - & 1435 & 1439 \\
\hline 11 & 27.993 & $($ E,E)- $\alpha$-Farnesen & 0.25 & - & 1506 & 1512 \\
\hline 12 & 47.732 & Abietadien & - & 0.33 & 2057 & 2056 \\
\hline 13 & 52.923 & Neofitadien & 3.65 & 0.33 & 2218 & 2224 \\
\hline \multicolumn{7}{|l|}{ Terpenoidler } \\
\hline 14 & 6.863 & Cis-Dihidroksi Linalool oksit & 0.23 & 0.91 & 1008 & 1011 \\
\hline 15 & 9.161 & Cis-Linalool oksit & - & 0.51 & 1087 & 1087 \\
\hline 16 & 9.827 & trans-Linalool oksit & - & 0.75 & 1092 & 1094 \\
\hline 17 & 10.461 & Linalool & 1.15 & - & 1097 & 1111 \\
\hline 18 & 12.773 & Pinokarvon & 0.47 & - & 1165 & 1168 \\
\hline 19 & 13.071 & Borneol & 0.36 & - & 1169 & 1174 \\
\hline 20 & 13.541 & Terpinen-4-ol & 0.78 & - & 1177 & 1184 \\
\hline
\end{tabular}


Tablo 1'in devamı

\begin{tabular}{|c|c|c|c|c|c|c|}
\hline No & Alık. Zam. & Bileşiğin Adı & $\begin{array}{l}\text { Çiçek } \\
\% \text { Alan }\end{array}$ & $\begin{array}{l}\text { Yaprak } \\
\% \text { Alan }\end{array}$ & $\begin{array}{l}\text { Literatür } \\
\text { RI }\end{array}$ & $\begin{array}{c}\text { Deneysel } \\
\text { RI }\end{array}$ \\
\hline 21 & 14.240 & $\alpha$-Terpineol & 0.44 & - & 1189 & 1195 \\
\hline 22 & 30.287 & (E)-Nerolidol & 0.63 & 1.1 & 1563 & 1570 \\
\hline 23 & 32.760 & $\alpha$-Bisabolol & - & 2.38 & 1686 & 1686 \\
\hline 24 & 49.651 & Fitol & 18.56 & 8.94 & 2117 & 2125 \\
\hline \multicolumn{7}{|c|}{ Terpenoid benzeri bileşikler } \\
\hline 25 & 22.566 & $(E)-\beta$-Damaskonen & 0.33 & 1.1 & 1385 & 1388 \\
\hline 26 & 24.459 & $(E)-\beta$-Ionen & 0.30 & 0.65 & 1430 & 1433 \\
\hline 27 & 40.816 & Hekzahidrofarnesil aseton & 0.57 & 0.96 & 1848 & 1852 \\
\hline \multicolumn{7}{|c|}{ Hidrokarbonlar } \\
\hline 28 & 4.743 & Nonane & - & 2.94 & 900 & 896 \\
\hline 29 & 5.870 & (4,4)-Dimetil-2-penten & - & 2.77 & 963 & 966 \\
\hline 30 & 6.595 & Dekan & 0.35 & - & 1000 & 1002 \\
\hline 31 & 10.224 & Undekan & - & 1.34 & 1100 & 1104 \\
\hline 32 & 14.465 & Dodekan & 0.41 & 0.95 & 1200 & 1203 \\
\hline 33 & 18.891 & Tridekan & 0.1 & 1.68 & 1300 & 1304 \\
\hline 34 & 23.299 & Tetradekan & 0.43 & 1.22 & 1400 & 1403 \\
\hline 35 & 27.501 & Pentadekan & - & 0.94 & 1500 & 1499 \\
\hline 36 & 31.559 & Hekzadekan & 0.54 & 0.51 & 1600 & 1598 \\
\hline 37 & 34.765 & Heptadekan & 1.24 & 10.05 & 1700 & 1701 \\
\hline 38 & 36.420 & $\begin{array}{l}(1,1,1-) \text { Siklobüten, bis }(1,2) \\
\text { diil-Benzen }\end{array}$ & - & 2.88 & 1788 & 1784 \\
\hline 39 & 39.125 & Oktadekan & 0.24 & - & 1800 & 1803 \\
\hline 40 & 42.683 & Nonadekan & 0.98 & - & 1900 & 1902 \\
\hline 41 & 46.050 & Eikosan & 0.83 & - & 2000 & 2004 \\
\hline 42 & 49.227 & Heneikosan & - & 3.03 & 2100 & 2102 \\
\hline 43 & 52.367 & Dokosan & 1.05 & - & 2200 & 2203 \\
\hline 44 & 55.146 & Trikosan & 5.67 & 0.92 & 2300 & 2305 \\
\hline 45 & 58.136 & Tetrakosan & 1.29 & - & 2400 & 2400 \\
\hline 46 & 60.976 & Pentakosan & 3.39 & 1.66 & 2500 & 2501 \\
\hline \multicolumn{7}{|c|}{ Alkoller } \\
\hline 47 & 9.525 & Oktanol & 9.01 & - & 1068 & 1073 \\
\hline 48 & 34.530 & Tetradekanol & 1.57 & 0.97 & 1673 & 1675 \\
\hline 49 & 36.055 & (E)-2-Tetradesen-1-ol & 0.32 & 2.30 & 1713 & 1720 \\
\hline 50 & 47.499 & Oktadekanol & 25.40 & 6.3 & 2078 & 2065 \\
\hline 51 & 54.373 & Eikosanol & - & 5.17 & & \\
\hline \multicolumn{7}{|c|}{ Diğer bileşikler } \\
\hline 52 & 6.666 & Oktanal & 0.43 & - & 999 & 1004 \\
\hline 53 & 18.230 & Edulan-I hidro & 0.82 & 3.78 & 1289 & 1290 \\
\hline 54 & 18.736 & Undekanon & 0.20 & - & 1294 & 1300 \\
\hline 55 & 19.307 & Undekanal & 0.31 & - & 1310 & 1314 \\
\hline 56 & 23.753 & Dodekanal & 0.28 & - & 1409 & 1415 \\
\hline 57 & 27.511 & 2-Tridekanon & 2.72 & - & 1496 & 1502 \\
\hline 58 & 28.085 & Tridekanal & 0.47 & 0.97 & 1510 & 1516 \\
\hline 59 & 28.634 & Metil laurat & 0.62 & - & 1526 & 1528 \\
\hline 60 & 32.154 & Tetradekanal & 0.48 & 0.51 & 1613 & 1620 \\
\hline 61 & 36.466 & Metiltetradekanoat & 0.67 & 8.04 & 1724 & 1727 \\
\hline 62 & 40.169 & Siklopentadekanolit & 0.51 & & 1834 & 1834 \\
\hline 63 & 42.620 & Etil linoleat & - & 2.05 & 1891 & 1895 \\
\hline 64 & 43.630 & Metil hekzaadekanoat & 0.94 & 1.36 & 1922 & 1925 \\
\hline 65 & 50.256 & Metil oktadekanoat & 0.86 & - & 2125 & 2127 \\
\hline \multirow[t]{2}{*}{66} & 52.704 & Oktadekanol asetat & 1.01 & - & 2210 & 2215 \\
\hline & & Toplam & $\% 95.34$ & $\% 82.4$ & & \\
\hline
\end{tabular}


Literatürde C. palustris bitkisinin çiçek kısmındaki erkek organ kısmının termal desopsiyon GC-MS analizi yapılmış olup 39 adet uçucu bileşen aydınlatıldığ 1 rapor edilmiştir (Andreas vd., 2004) ve uçucu ana bileşenleri; seskiterpenoit (\%47.4), yağ asidi $(\% 27.1)$ ve monoterpenoit $(\% 23.0)$ olarak tespit edilmiştir (Jürgens ve Dötterl, 2004).

Yapılan çalışmada $C$. palustris bitkisinin çiçek kısmındaki erkek organ kısmının uçucu bileşenlerin eldesi ve aydınlatma yöntemlerinde farklılıklar olduğu görülmektedir ve çiçek kısmının ana bileşenlerinin alkol (\%36.30), terpenoid (\%22.60) ve hidrokarbon (\%16.52) sınıfi bileşikler olduğu bulunmuştur. Terpenoit bileşiklerden en fazla diterpenoit $(\% 18.56)$ ve monoterpenoit (\%3.43) bulunmuşken; literatürde- ki çalışmada ise seskiterpenoit (\%47.4) ve monoterpenoit (\%23.0) bileşikleri farklı oranlarda tespit edilmiştir. Yöntem farklılığı ve bitkinin toplanma yeri açısından çalışmalar arasında oldukça büyük farklılıklar bulunmaktadır. Çiçek kısımların uçucu yağ bileşimleri karşılaştırıldığında terpen ve terpenoid sınıfi bileşiklerden; cis-linalool oksit (\%0.09), $\alpha$-santalen (\%0.25), $\alpha$ bergamaton $(\% 0.36),(\mathrm{E}, \mathrm{E})-\alpha$ farnesene $(\% 0.25)$, yağ asidi esteri bileşikleri, octanal (\%0.043), dodecanal (\%0.28), hekzadekan (\%0.55) bileşiklerinin iki çalışmada da tespit edildiği fakat uçucu yağların genel bileşimleri ve bileşen sınıfları açısından birbirinden büyük oranda farkl11ık gösterdiği görülmektedir. Literatürde $C$. palustris bitkisinin yaprak kısmının uçucu yağ bileşimine ait herhangi bir çalışmaya rastlanmamıştır.

Tablo 2. C. palustris Çiçek ve Yaprak Kısımlarının Uçucu Yağ Bileşen Sınıfları

\begin{tabular}{|l|c|c|l|c|c|l|}
\hline & \multicolumn{3}{|c|}{ Çiçek } & \multicolumn{3}{c|}{ Yaprak } \\
\hline Bileşikler & \%Alan & Say1 & Ana Bileşik & \%Alan & Say1 & Ana Bileşik \\
\hline Terpenler & 8.38 & 10 & Neofitadien & 2.76 & 4 & $(E)$ - $\beta$-Farnesan \\
\hline Terpenoidler & 22.62 & 8 & Fitol & 14.59 & 6 & Fitol \\
\hline $\begin{array}{l}\text { Terpenoid benzeri } \\
\text { bileşikler }\end{array}$ & 1.2 & 3 & $\begin{array}{l}\text { Hekzahidrofarnesil } \\
\text { aseton }\end{array}$ & 2.71 & 3 & $(E)$ - $\beta$-Damaskonen \\
\hline Hidrokarbonlar & 16.52 & 13 & Trikosan & 30.89 & 13 & Heptadekan \\
\hline Alkoller & 36.30 & 4 & Oktadekanol & 14.74 & 4 & Oktadekanol \\
\hline Diğer bileşikler & 10.32 & 14 & 2-Tridekanon & 16.71 & 6 & Metil tetradekanoat \\
\hline Total & $\% 95.34$ & 52 & & $\% 82.4$ & 36 & \\
\hline
\end{tabular}

C. palustris bitkisinin çiçek ve yaprak kısmının uçucu yağ ekstraktlarının seçilen 8 adet mikrooraganizmaya karşı antimikrobiyal aktivite test sonuçları Tablo 3'de verilmiştir. Antimikrobiyal aktivite testleri sonucunda, uçucu yă ekstraktlarının antibakteriyel aktivitelerinin olmadığı, inhibisyon zone çapları ölçümü sonucunda maya mantarlarına karşı orta düzeyde (8-14 mm çapında) antimikotik etkinliğin var olduğu bulunmuştur. Çiçek kısmının uçucu yağının antimikotik etkinliğinin (12-14 $\mathrm{mm})$, yaprak kısmına göre $(8-10 \mathrm{~mm})$ daha yüksek olduğu belirlenmiştir.

Literatürde, C. palustris var. alba bitkisinin Soxhlet ekstraksiyonu yöntemiyle petrol eteri, kloroform ve metanol çözücüleriyle elde edilen ekstraktların antimikrobiyal, antioksidan ve sitotoksik aktivite çalışması bulunmaktadır (Mubashir vd., 2014). Metanol ekstraktın diğer çözücü ekstraklarından daha iyi sonuç vermesi sebebiyle biyolojik aktivite testlerini metanolik ekstrakt gram pozitif ve gram negatif bakterilere (Pseudomonas aeruginosa MTCC 1688, Proteus vulgaris MTCC 426, Bacillus subtilis MTCC 441, Staphylococcus epidermidis MTCC 435 ve Staphylococcus aureus MTCC 96 bakterilerinden sadece $S$. epidermidis ve $P$. Vulgaris) karşı oldukça yüksek kabul edilen 24-23 mm zone çapı oluşturduğu belirtilmiştir. Yapılan bu çalışmada; C. palustris bitkisinin çiçek ve yaprak kısımlarının subuharı destilasyonu ile elde dilen uçucu yağların sadece maya mantarları olan $C$. albicans ve $S$. cerevisiae bakterilerine orta düzey olarak kabul edilen 8-14 $\mathrm{mm}$ zone çapları arasındaki değerlerde aktivite gösterdiği bulunmuştur. Çalışmadaki bitkilerin C. palustris ve $C$. palustris var. alba nin toplandığı bölgelerin ve çevrelerinin farklı olması, hemde yapılan ekstraksiyon yöntemindeki çözücülerin farklı olmas1 sebebiyle antimikrobiyal aktivite testlerinde birbirinden farklı mikroorganizmalara karşı aktivite bulunması oldukça olağan olarak yorumlanabilir. 
Table 3. C. palustris Bitkisinin Çiçek ve Yapraklarından Elde Edilen Uçucu Yağların Antimikrobiyal Aktiviteleri $(50 \mu \mathrm{L})$.

\begin{tabular}{|l|c|c|c|c|c|c|c|c|c|}
\hline \multirow{2}{*}{ C. palustris } & \multirow{2}{*}{$\begin{array}{c}\text { Stok } \\
(\mu \mathrm{g} / \mathrm{mL})\end{array}$} & \multicolumn{6}{|c|}{ Mikroorganizmalar ve İnhibisyon zone çapları (mm) } \\
\cline { 3 - 10 } & $\mathbf{E c}$ & $\mathbf{Y p}$ & $\mathbf{P a}$ & $\mathbf{S a}$ & $\mathbf{E f}$ & $\mathbf{B s}$ & $\mathbf{C a}$ & Sc \\
\hline Çiçek & 1000 & - & - & - & - & - & - & 12 & 14 \\
\hline Yaprak & 1000 & - & - & - & - & - & - & 8 & 10 \\
\hline
\end{tabular}

Ec: Escherichia coli ATCC 25922, Yp: Yersinia pseudotuberculosis ATCC 911, Pa: Pseudomonas aeruginosa ATCC 43288, Sa: Staphylococcus aureus ATCC 25923, Ef: Enterococcus faecalis ATCC 29212, Bc: Bacillus cereus 702 Roma, Ca: Candida albicans ATCC 60193, Saccharomyces cerevisiae RSKK 251, Amp.: Ampicillin, Flu.: Fluconazole, (-): no activity.

\section{Teşekkür}

Yapılan çalışma, Karadeniz Teknik Üniversitesi BAP birimi tarafından desteklenmiştir. Antimikrobiyal aktivite testlerini yapan Prof. Dr. Şengül Alpay Karaoğlu'na teşekkürlerimizi sunariz.

\section{Kaynaklar}

Adams, R.P., 2004., Identification of essential oil components by gas chromatography/mass Spectrometry. 4th Ed., Allured publishing Corp., Carol Stream, Illinois. 1-698.

Ali, H., Nisar, M., Jehandar, S., 2011, Ethnobotanical study of some elite plants belonging to Dir, Kohistan Valley, Khyber Pu-khtunkhwa, Pakistan [J]. Pak J Bot, 43(2): 787-795.

Baykal, T., Bedir, E., Calis, I., Aquino, R., Piacente S., Pizza, C., 1999, Two oleanene glycosides from the aerial parts of Caltha polypetala, Phytochemistry 51:1059-1063.

Baytop, T. 1984. Therapy with medicinal plants in Turkey (past and present), Publications of Istanbul University, 3255(40), İstanbul, Turkey.

Bhandari, P and Rastogi, R.P, 1984, Triterpene constituents of Caltha palustris, Phtyochemistry, 23(9); 2082-2085.

Bhandari, P and Rastogi, R.P, 1984, Two nor-triterpene lactones from Caltha palustris, Phtyochemistry, 23(8); 1699-1702.

Birinci, S., 2008, Doğu Karadeniz Bölgesinde Doğal Olarak Bulunan Faydalı Bitkiler ve Kullanım Alanlarının Araştırılması. Çukurova Üniversitesi Fen Bilimleri Enstitüsü, Yüksek Lisans Tezi, s.143.

Bonora, A., Tosi B., Donini A., Botta B., Bruni A., 1987, Elicitor-induced Accumulation of Protoanemonin in Caltha palustris L., Journal of Plant Physiology 131(5), 489-494.

Cansu, T. B., Yücel, M., Sinek, K., Baltacı, C., Karaoglu, A. Ş. ve Yaylı N., 2011, Microwave
Assisted Essential Oil Analysis and Antimicrobial Activity of M. Alpestris Subsp. Alpestris, Asian Journal Of Chemistry, 23(3), 1029-1031.

Davis, P. H., 1965-1985, Flora of Turkey and the East Aegean Island Vol.:I and Supplament, Edinburg: Edinburg Univesity Press.

Dickenmann R., 1982, Cyanogenesis in Ranunculus montanuss from the Swiss Alps [J], Bericht des Geobotanischen Institutes ETH, 49(1): 56-75.

Ekmekçigil M., 2006, Ankara Üniversitesi Fen Fakültesi herbaryumu (ANK) Ranunculaceae familyası revizyonu, Ankara Üniversitesi Fen Bilimleri Enstitüsü, Yüksek Lisans Tezi, s.105, Ankara.

Ellnain-Wojtaszek, M., Kowalewski, Z., Bialecka, L., 1991, Flavonoid compounds in flowers of Caltha palustris L. (Ranunculaceae), Herba Polonica 37(3-4), 125-132.

Fancelloa, F., Zaraa, S., Petrettob, G. L., Chessab M., Addisb R., Rourkec J. P. and Pintoreb, G., 2017, Essential oils from three species of Mentha harvested in Sardinia chemical characterization and evaluation of their biological activity, International Journal of Food Properties, 20(2), 1751-1761.

Figurkin, B.A., Khidasheli, V.D., Pidemskii, E.L., Goleneva, A.F., 1978, Triterpenoid glycosides of Caltha palustris L. and their effect on some biochemical indexes of the blood serum of rats, Rastitel'nye Resursy 14(1), 93-95.

Güner, A., Aslan, S., Ekim, T., Vural, M., Babaç, M.T. (edlr.), 2012. Türkiye Bitkileri Listesi (Damarlı Bitkiler). Nezahat Gökyiğit Botanik Bahçesi ve Flora Araştırmaları Derneği Yayını. İstanbul.

Ibanez, S., Dotterl, S., Anstett, M.C., Baudino, S., Caissard, J.C., Gallet, C. ve Despre's, L., 2010, The role of volatile organic compounds, morphology and pigments of globeflowers in the attraction of their specific pollinating flies, New Phytologist, 188: 451-463. 
Jurgens, A. ve Dötterl S., 2004, Chemical Composition of Anther Volatiles in Ranunculaceae: GeneraSpecific Profiles in Anemone, Aquilegıa, Caltha, Pulsatılla, Ranunculus and Trollius Species, American Journal of Botany, 91(12): 1969-1980.

Kumar, P. ve Singhal V. K., 2008, Cytology of Caltha palustris L. (Ranunculaceae) from Cold Regions of Western Himalayas, Cytologia 73(2): 137-143.

Küçükkurt, İ. ve Fidan, A.F., 2008, Saponinler ve Bazı Biyolojik Etkileri, Kocatepe Veteriner Dergisi, 1: 89-96.

Mubashir, S., Dar M.Y., Lone B. A., Zargar M. I., Shah W. A., 2014, Anthelmintic, antimicrobial, antioxidant and cytotoxic activity of Caltha palustris var. alba Kashmir, India, Chinese Journal of Natural Medicines, 12(8): 567-572.

NIST Chemistry Webbook, NIST Standart Reference Database Version 147.

Radulovi'c, N.S., Dordevi'c, A.S., Zlatkovi'c, B. K., Pali', R. M., 2009, GC-MS analyses of flower ether extracts of Prunus domestica L. and Prunus padus L. (Rosaceae), Chemical Papers, 63 (4) 377-384.

Roner, M.R., Sprayberry, J., Spinks, M. ve Dhanji, S., 2007, Antiviral Activity Obtained from Aqueous Extracts of the Chilean oapbark tree (Quillaja saponaria Molina), J. Gen Virol, 88, 275-285.

Schuettpelz, E. ve Hoot, S. B., 2004, Phylogeny and Biogeography of Caltha (Ranunculaceae) Based on Chloroplast and Nuclear Dna Sequences, American Journal of Botany 91(2): 247-253.

Seago Jr, J.L., Peterson C. A., Kinsley L. J., Broderick J., 2000, Development and Structure of the Root Cortex in Caltha palustris L. and Nymphaea odorata Ait, Annals of Botany 86(3) 631-640.

Smith Jr. C. R., Kleiman, R., Wolff, I. A., 1968, Caltha palustris L. Seed Oil. A source of four fatty acids withcis-5-unsaturation, Lipids, 3(1): 3742.

Suszko, A. and Obmińska-Mrukowicz, B., 2013, Influence of polysaccharide fractions isolated from Caltha palustris L. on the cellular immune response in collagen-induced arthritis (CIA) in mice. A comparison with methotrexate, Journal of Ethnopharmacology, 145(1), 109-117.

Tóth, A., Lakatos T., Braun M. Kiss B., 1999, Ramet distribution, leaf morphometry and elemental composition of Caltha palustris L. along a water depth gradient, Flora 194(4), 431-437.
Tyagi, V., Patel, R., Hazarika, H., Dey P., Goswami, D. ve Chattopadhyay P., 2017, Chemical composition and bioefficacy for larvicidal and pupicidal activity of essential oils against two mosquito species, International Journal of Mosquito Research, 4(4): 112-118.

URL-1:

http://www.theplantlist.org/1.1/browse/A/Ranun culaceae/Caltha/ (Erişim tarihi: 24 Nisan 2018).

Üçüncü, O., Baltac1, C. ve İlter Ş. M., 2016, Gladiolus italicus Miller Bitkisinin Uçucu Yağının Kimyasal Bileşimi ve Biyoaktif Özellikleri, GÜFBED/GUSTIJ, 6 (2): 150-156.

Van der Welle, M.E.W., Niggebrugge, K., Lamers, L.P.M., Roelofs, J.G.M., 2007, Differential responses of the freshwater wetland species Juncus effusus L. and Caltha palustris L. to iron supply in sulfidic environments, Environmental Pollution, 147, 222-230.

Vugalter M. M., Dekanosidze G. E., Dzhikiya O. D., Shashkov A. S., Kemertelidze É. P., 1988, Triterpene saponins of Caltha polypetala Glycosides G and I., Chemistry of Natural Compounds 24(2), 193-200.

Wink, M., 2009, Mode of action and toxicology of plant toxins and poisonous plants, Mitt. Julius Kühn-Inst. 421, 93-112.

Woodell, S. R. J. ve Kootin, S.,1971, Intraspecific variation in Caltha palustris, New Phytol. 70: 173-186.

Yaylı, N., Yaşar, A., İskender, N. Y., Yaylı, N., Cansu T.B., Coskunçelebi, K. ve Karaoğlu, Ş., 2010, Chemical constituents and antimicrobial activities of the essential oils from Sedum pallidum var. bithynicum and S.spurium Grown in Turkey, Pharm. Biol . 48(2), 191-194

Yeşilyurt, E. B., Çetin, Ö. ve Gürbüz, Y., 2016, Konya (Pseudodelphinium Turcicum) Mevzek Tür Eylem Planı, T.C. Orman Ve Su İşleri Bakanlığı Doğa Koruma ve Milli Parklar Genel Müdürlüğü, s.2.

Yücel, T.B., Karaoğlu A. Ş. ve Yaylı N., 2017, Antimicrobial Activity and Composition of Rindera lanata (LAM.) Bunge var. canescens (A.D.C.) Kosn. Essential oil Obtained by Hydrodistillation and Microwave Assisted Distillation, Rec. Nat. Prod. 11:3, 328-333.

Zelenina M.V.,1980, Localization of triterpenoid glycosides in Anemone ranunculoides L., Ficaria verna Huds. and Caltha palustris L. of the Ranunculaceae family, Rastitel'nye Resursy 16(2), 235-237. 